\title{
SEA systems in the Middle East and North Africa region
}

\author{
G. Rachid \& M. El Fadel \\ Department of Civil and Environmental Engineering, \\ American University of Beirut, Beirut, Lebanon
}

\begin{abstract}
Globally, Strategic Environmental Assessment (SEA), a decision support tool that integrates environmental considerations into policies, plans and programs, has played an appreciable role in the decision making on land use planning, transportation policies, development sectors and infrastructure plans. This paper discusses the application and performance of SEA in the Middle East and North Africa region through a comparative assessment of existing and potential legal, institutional and procedural SEA frameworks. The research methodology involves both countries' self-assessment of their SEA system through openended surveys and country analysis of SEA national application and structure. The results show varied levels of weaknesses embedded in the legal and administrative frameworks and poor integration with the decision making process. Capitalizing on current opportunities, the paper highlights measures to enhance the development and enactment of SEA in the region.

Keywords: SEA, legal and institutional frameworks, performance, MENA region.
\end{abstract}

\section{Introduction}

The rationale for strategic environmental assessment (SEA) stems from the need for an approach that extends beyond the downstream analysis and mitigation of adverse impacts of development while catering for the interdependency of poverty, development, growth and environment. Its unique feature lies in integrating environmental considerations at a high level of decision making and ensuring an early warning of cumulative and synergistic effects leading to largescale changes. Since the enactment of the 2001/42/EC European Council SEA Directive and the Kiev 2003 Protocol, SEA has been on a rising trend of 
adoption with further mainstreaming by international legal and policy developments. Today, its implementation has become common practice in developed countries with increased momentum worldwide where around forty countries are known to have formal SEA systems (Noble [1]; Abaza et al. [2], Partidario [3]). Countries with economies in transition are also increasingly mainstreaming SEA in their policy planning (Sanchez and Sanchez [4]; Garfi et al. [5]; Sheate and Partidario [6]; ECA [7]) while its application in developing countries remains limited albeit a slow progress promoted mostly by international organizations. Although there is a consensus on the need to evaluate SEA implementation and performance, comparative assessment of SEA systems has not been widely reported (Retief et al. [8]; Chaker et al. [9]; Cashmore et al. [10]; Partidario and Fischer [11]; Sadler [12]; Dalal-Calyton and Sadler [13]). This paper evaluates SEA application and performance in the Middle East and North Africa (MENA) region through a comparative assessment of related legal, institutional, and procedural frameworks while outlining future needs to enhance the effectiveness and mainstreaming of SEA implementation in the region.

\section{Methodology}

The MENA region, consisting of 20 countries (Algeria, Bahrain, Egypt, Iran, Iraq, Israel, Jordan, Kuwait, Lebanon, Libya, Morocco, Palestinian Authority, Oman, Qatar, Kingdom of Saudi Arabia (KSA), Syria, Tunisia, Turkey, United Arab Emirates (UAE) and Yemen), spans over a geographical area of $8.7 \mathrm{M} \mathrm{km}^{2}$ that is disproportionally populated and endowed with natural resources. While all suffer from similar environmental problems consisting mainly of water scarcity, land, coastal and marine degradation, and weak environmental institutions (Tolba and Saab [14]), country-specific environmental management is defined by the varying severity of these challenges, as well as by the diversity of political systems and policy making processes that exist among countries exhibiting different levels of transparency, accountability, efficiency and effectiveness.

The methodology consisted of evaluating and comparing SEA systems within an analytical framework based on pre-defined evaluation criteria. The use of a systematic framework to evaluate SEA systems has been promoted with criteria based on SEA contribution to decision-making (Sanchez and Sanchez [4]; DalalClayton and Sadler [13]) as well as by performance criteria for the evaluation of the effectiveness of existing SEA processes (Retief [15]; IAIA [16]). While, it is argued that different criteria should be used to evaluate SEA systems in countries with different planning systems (Marsden [17]; Fischer and Gazzola [18]; Retief [15]), common criteria were used for the comparative assessment in this study based on four performance areas: institutionalization, implementation process and application, review, and influence on decision making, within which seven performance criteria were evaluated with 17 performance indicators (Table 1). Data were compiled from relevant literature supplemented with countries' selfassessment of their SEA systems and experiences through open-ended surveys. The surveys, circulated to accessible focal points at relevant national authorities in 14 countries, examined legal and operational frameworks for examples of 
Table 1: $\quad$ Evaluation criteria.

\begin{tabular}{|c|c|c|}
\hline Performance area & Performance Criterion & Performance Indicator \\
\hline \multirow{5}{*}{$\begin{array}{l}\text { Institutionalization } \\
\text { of SEA }\end{array}$} & \multirow[t]{3}{*}{ Legal Framework } & Enabling legislation for SEA exits \\
\hline & & Specific SEA legislation for SEA exists \\
\hline & & SEA guidelines exist \\
\hline & \multirow[t]{2}{*}{$\begin{array}{l}\text { Administrative } \\
\text { Framework }\end{array}$} & $\begin{array}{l}\text { Competent Responsible Authority(ies) for } \\
\text { SEA specified }\end{array}$ \\
\hline & & $\begin{array}{c}\text { Competent Authority(ies) for SEA Preparation } \\
\text { defined }\end{array}$ \\
\hline \multirow{3}{*}{$\begin{array}{c}\text { SEA } \\
\text { implementation } \\
\text { process and } \\
\text { application }\end{array}$} & $\begin{array}{l}\text { SEA Application } \\
\text { Level }\end{array}$ & $\begin{array}{l}\text { SEA is applied to plans and/or programs } \\
\text { and/or policies }\end{array}$ \\
\hline & SEA type & $\begin{array}{c}\text { SEA conducted is sectoral and/or } \\
\text { programmatic and/or cumulative and/or } \\
\text { regional }\end{array}$ \\
\hline & SEA Process & $\begin{array}{l}\text { Steps included in the SEA process: screening; } \\
\text { scoping; impacts; alternatives; impact } \\
\text { mitigation; public participation }\end{array}$ \\
\hline \multirow[t]{3}{*}{ SEA review } & \multirow[t]{3}{*}{ Review Process } & Competent Authority for SEA Review defined \\
\hline & & Review process procedures exist \\
\hline & & SEA Quality \\
\hline \multirow[t]{2}{*}{$\begin{array}{l}\text { SEA influence on } \\
\text { decision making }\end{array}$} & \multirow[t]{2}{*}{ SEA impact } & $\begin{array}{l}\text { SEA results are adopted in decision making } \\
\text { process }\end{array}$ \\
\hline & & SEA included implementation monitoring \\
\hline
\end{tabular}

successful SEAs and lessons learnt, and the local challenges and weaknesses to SEA implementation.

\section{Results and discussion}

The survey, although complemented the data collection process, had a response rate of 42 percent. Further, the disparity, inconsistency and inequality in the scope and scale of accessible country-specific data presented a limitation to the analysis. As such, while SEA experiences and implementation is discussed for all countries, the comparative assessment is limited to countries with existing SEA frameworks or SEA studies, about 12 of the 20 countries examined.

\subsection{SEA institutionalization}

All examined MENA countries have general enabling as well as EIA legislation which often overlap with their framework laws on environment. In contrast, specific SEA legislation (Table 2) is at different stages of development in the region. About 14 countries do not have any kind of SEA legislation whereas Lebanon has a recently enacted SEA legislation; Turkey has a draft one while KSA, Qatar and Israel, although request environmental assessment of plans, still categorize it within EIAs. Furthermore, Morocco, Yemen and UAE are in the process of updating their legislation whereas Egypt is requesting SEAs based on the existing enabling legislation. In Jordan, Oman, Tunisia and Qatar SEAs are conducted despite the absence of specific legislation. Note that the Emirate of Abu Dhabi enacted technical guidelines in 2010 unilaterally to organize SEA implementation in the Emirate. 


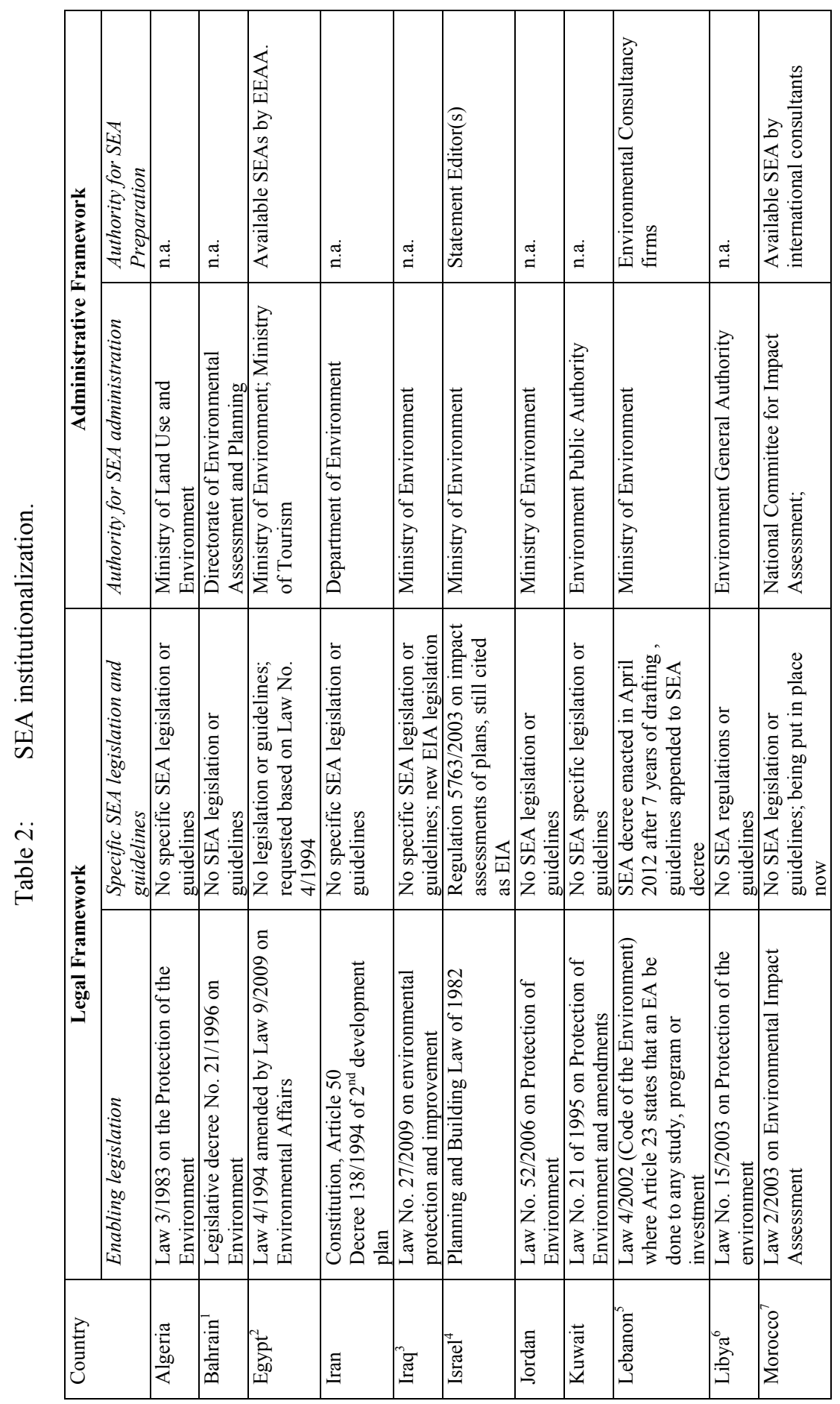




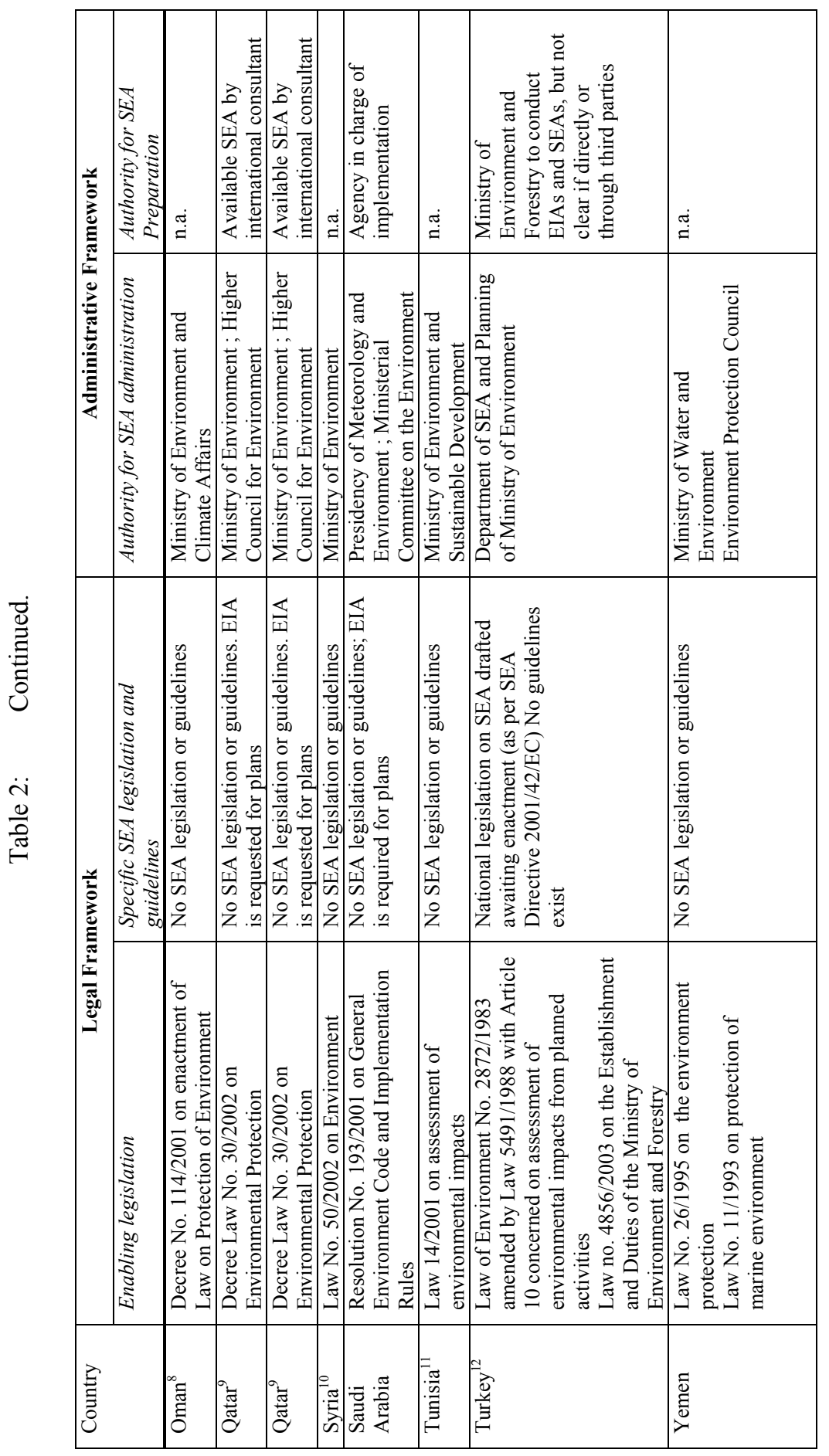



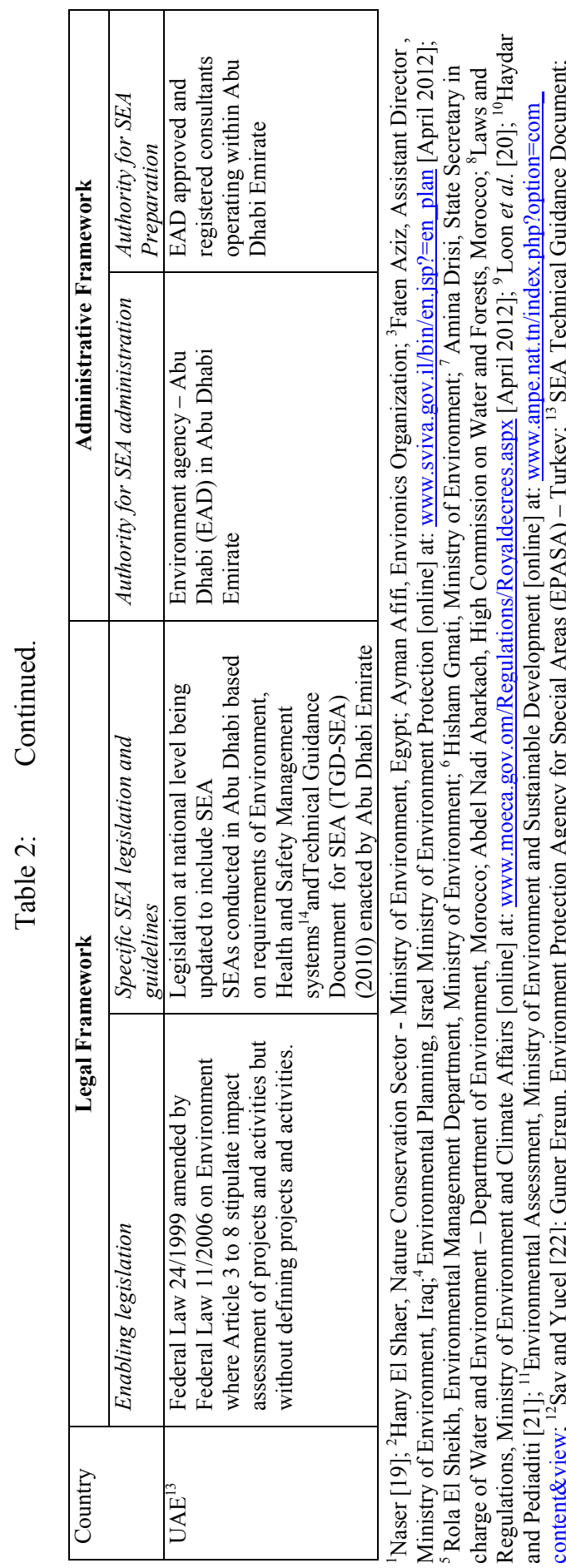

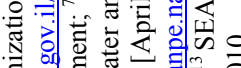

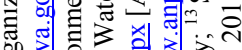

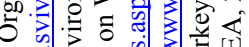

के

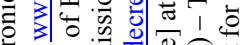

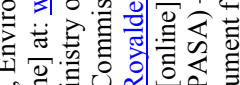

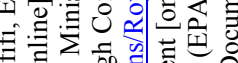

远.

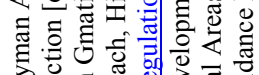

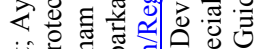

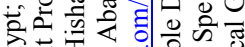

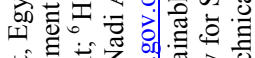

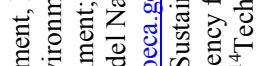

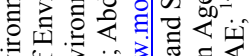

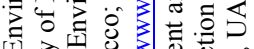

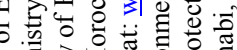

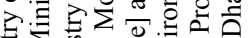

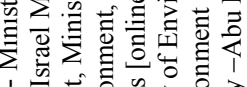

के ôी

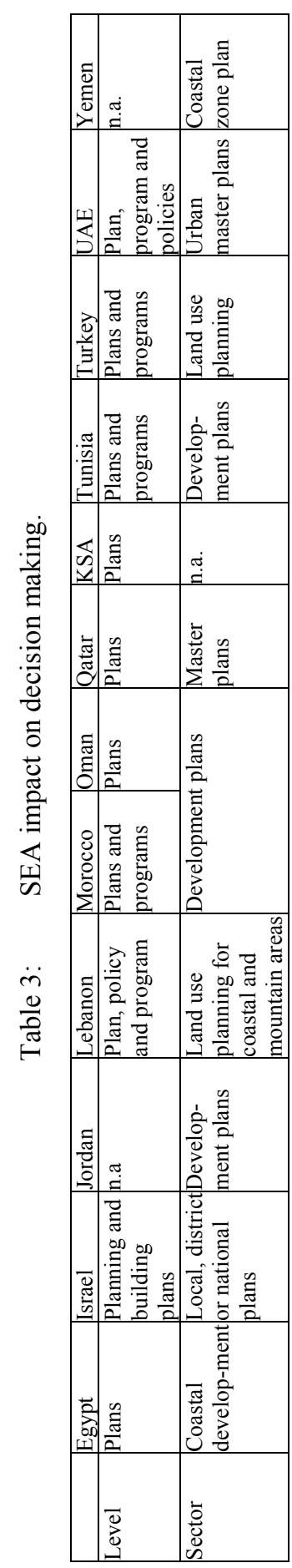

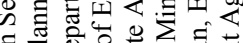

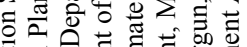

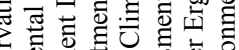

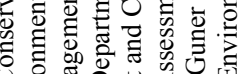

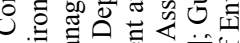
茨

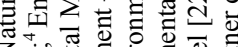

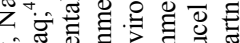

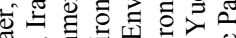

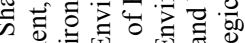

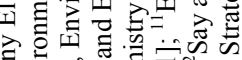

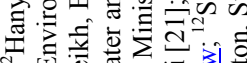

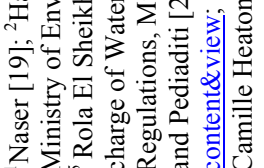




\subsection{SEA influence on decision making}

Success stories of SEA implementation are reported in the countries' self assessment of their SEA status (Table 4). The pilot projects in Turkey and Lebanon have been successful in demonstrating the SEA process, involving stakeholders and recommending changes to proposed plans. In view of their pilot nature, it is not apparent whether decision makers will consider the SEA findings and recommendations in plans. Focused on spatial planning, development SEAs for Al-Aqaba Area and the Red sea were considered successful by the Egyptian Ministry of Environment in broadening available alternatives and foreseeing mitigation measures. In Morocco, a series of agriculture and fisheries' related projects developed within a compact development program administered by the government for five years were reported to present success stories of SEA implementation. In Tunisia and Abu Dhabi, SEAs highlighted unforeseen impacts associated with infrastructure programs that required halting and modifying the programs. The current focus appears to be on mainstreaming SEA and hence it is too early to discuss the influence of SEA on decision making at a stage where decision makers have not yet enacted SEA legislation. Nevertheless, the requirements to include SEA findings in plans (Egypt), and of summarizing SEA outputs and required changes to plans (Lebanon, Turkey) reflect that envisioned SEA systems aim at influencing decision making.

Table 4: $\quad$ SEA impact on decision making.

\begin{tabular}{|c|c|c|}
\hline Country $^{1}$ & $\begin{array}{l}\text { SEA results incorporated in decision } \\
\text { making process }\end{array}$ & SEA success stories \\
\hline Egypt & $\begin{array}{l}\text { SEA results supported and guided } \\
\text { decision making process and improved } \\
\text { plans; SEA is included in the plan } \\
\text { document }\end{array}$ & $\begin{array}{l}\text { Gulf of Aqaba development plan } \\
\text { SEA } \\
\text { Red Sea development plan SEA }\end{array}$ \\
\hline Israel & $\begin{array}{l}\text { SEA integrated in regional development } \\
\text { planning processes }\end{array}$ & Galilee Development Plan \\
\hline Jordan & $\begin{array}{l}\text { SEA are undertaken in parallel to } \\
\text { planning process }\end{array}$ & Red Sea Area Development Plan \\
\hline Lebanon & $\begin{array}{l}\text { SEA influence on decision making is } \\
\text { not clear }\end{array}$ & $\begin{array}{l}\text { Tannourine Land use master plan as } \\
\text { pilot SEA study }\end{array}$ \\
\hline Morocco & $\begin{array}{l}\text { Conducted SEAs influence on decision } \\
\text { making is not clear }\end{array}$ & n.a \\
\hline Oman & Not clear from available information & n.a \\
\hline Tunisia & $\begin{array}{l}\text { SEAs on infrastructure programs urged } \\
\text { halting of project }\end{array}$ & $\begin{array}{l}\text { Infrastructure programs; Tunis Gulf } \\
\text { Development plans }\end{array}$ \\
\hline Turkey $^{2}$ & $\begin{array}{l}\text { Pilot SEAs conducted preceded and } \\
\text { helped in SEA legislation drafting. }\end{array}$ & Only pilot SEAs were done \\
\hline $\mathrm{UAE}^{3}$ & $\begin{array}{l}\text { SEA report should not make } \\
\text { recommendations, or conclusions about } \\
\text { the proposed plans or programs within } \\
\text { the scope of EAD review }\end{array}$ & $\begin{array}{l}\text { Port Khalifa and Al Taweelah } \\
\text { Industrial Zone project: SEA induced } \\
\text { changes in port location and design }\end{array}$ \\
\hline
\end{tabular}

${ }^{1}$ Based on surveys; ${ }^{2}$ Unalan and Cowell $[23] ;{ }^{3}$ Camille Heaton, Strategic Partner of EAD, Abu Dhabi - UAE. 


\section{Conclusion and future outlook}

Countries in the MENA region are at different stages of SEA adoption and implementation; however, they are steadily evolving towards effective SEA systems, albeit very slowly, as is the case in many other places worldwide. Apart from Lebanon, there is no country in the MENA region that has a fully established functional system of SEA. Israel, UAE (Abu Dhabi) and Turkey have a relatively well forming SEA structure, although in Turkey, the interest in initiating SEA processes is highly driven by the desire to access the European Union. Tiering the SEA and planning processes and applying SEA to policies, programs and plans remain a major threat to proper implementation. The other MENA countries are facing threats that might impede and delay the SEA implementation and mainstreaming although it is being increasingly driven by the momentum of developmental projects. The current status in MENA countries also reveals an important gap in the available literature on SEA systems and implementation similar to most developing countries. Hence, this first attempt at evaluating SEA systems in the MENA region, presented through a comparative assessment of SEA status, implementation and processes, is to be followed by focused in depth country analysis including the assessment of cases of SEA studies as well as by assessment of individual country's strengths, opportunities, weaknesses and threats to pave efficient national roadmaps for effective implementation of SEA systems.

Capitalizing on available opportunities, MENA countries are encouraged to enhance the development and enactment of SEA legislation as well as to strengthen the institutional framework for SEA, to compensate for the lack of effective, transparent and systematic planning processes by clarifying the role of relevant authorities, ensuring proper training and capacity building for competent authorities on SEA legal, procedural and technical matters. In this context, specificities in the SEA legislation need to a) include screening and scoping stages in the procedural framework of SEAs and ensure all plans, programs and policies are subject to environmental assessment; b) improve cooperation, communication and coordination between SEA competent authorities and other public agencies for securing an enabling environment for proper SEA implementation; c) initiate SEA application to policies through pilot studies as a step to mainstreaming; d) continuously monitor SEA implementation to improve the process and adapt to decision making requirements; e) improve the quality of SEA reporting to increase the value added to decision making; f) close the gap between theory of SEA and the actual SEA practice in terms of SEA objectives, scope and outputs; and g) close the gap between SEA as an independent tool and decision making through tiering SEA to plan and policy-making processes.

\section{References}

[1] Noble, B., Promise and dismay: the state of strategic environmental assessment systems and practices in Canada, Environmental Impact Assessment Review, 29, pp. 66 -75, 2009. 
[2] Abaza, H., Bisset, R. and Sadler, B, Environmental Impact Assessment and Strategic Environmental Assessment: Towards an Integrated Approach: Economics and Trade Branch, United Nations Environment Program, Geneva, 2004.

[3] Partidario, M., Scales and associated data: what is enough for SEA needs? Environmental Impact Assessment Review, 27, pp. 460 - 478, 2007.

[4] Sanchez, L. and Sanchez, S.,T iering strategic environmental assessment and project environmental impact assessment in highway planning in Sao Paulo, Brazil, Environmental Impact Assessment Review, 28, pp. 515-522, 2008.

[5] Garfi, M., Ferrer-Marti, L., Bonoli, A. and Tondelli, S., Multi-criteria analysis for improving SEA of water programmes: a case study in semi arid region of Brazil, Journal of Environmental Management,92, pp. 665-675, 2011.

[6] Sheate, W. and Partidario, M., Strategic approaches and assessment techniques-Potential for knowledge brokerage towards sustainability, Environmental Impact Assessment Review, 30, pp. 278-288, 2008.

[7] ECA, Review of the Application of EIA in selected African Countries: Economic Commission of Africa, Ethiopia, ECA/SDD/05/13, 2005.

[8] Retief, F., Jones, C. and Jay, S., The Emperor's new clothes - Reflections on Strategic Environmental Assessment (SEA) practice in South Africa, Environmental Impact Assessment Review, 28, pp. 504-514, 2008.

[9] Chaker, A., El Fadl, K., Chamas, L. and Hatjian, B. A review of strategic environmental assessment in 12 selected countries, Environmental Impact Assessment Review, 26, pp. 15-56, 2006.

[10] Cashmore, M., Gwilliam, R., Morgan, R., Cobb, D. and Bond, A., The interminable issue of effectiveness: substantive purposes, outcomes and research challenges in the advancement of environmental impact assessment theory, Impact Assessment Project Appraisal, 22,pp. 295-310, 2004.

[11] Partidario, M. and Fischer, T., Follow-up in current SEA understanding, Assessing Impact: Handbook of EIA and SEA Follow-up, ed. MorrisonSaunders, A. and Arts, J., Earthscan: London, pp. 224-247, 2004.

[12] Sadler, B., On evaluating the success of EIA and SEA, Assessing impact: Handbook of EIA and SEA follow-up, ed. Morrison-Saunders, A. and Arts, J., Earthscan: London, pp. 248-285,2004.

[13] Dalal-Clayton, B. and Sadler, B., Strategic Environmental Assessment: A Sourcebook and Reference Guide to International Experience, Earthscan James and James: London, 2005.

[14] Tolba, M. and Saab, N., Arab Environment Future Challenges, 2008 Report of the Arab Forum for Environment and Development, Online:www.afedonline.org

[15] Retief, F., A performance evaluation of strategic environmental assessment (SEA) processes within the South African context, Environmental Impact Assessment Review, 27, pp. 84-100; 2007. 
[16] IAIA (International Association for Impact Assessment), Strategic Environmental Assessment Performance Criteria, IAIA Special Publication Series No.1, Fargo: IAIA, 2002.

[17] Marsden, S., Importance of context in measuring the effectiveness of strategic environmental assessment, Impact Assessment Project Appraisal,16(4), pp. 255-266, 1998.

[18] Fischer, T. and Gazzola, P., SEA good practice elements and performance criteria-equally valid in all countries? The case of Italy, Environmental Impact Assessment Review, 26(4), pp. 396-409, 2006.

[19] Naser, H., Evaluation of the Environmental Impact Assessment System in Bahrain, Journal of Environmental Protection, 3, pp. 233 - 239, 2012.

[20] Loon, L., Driessen, P., Kolhoff, A., and Runhaar, H., An analytical framework for capacity development in EIA - case of Yemen, Environmental Impact Assessment Review, 30, pp. 100-107, 2010.

[21] Haydar, F. and Pediaditi, K., Evaluation of the environmental impact assessment system in Syria, Environmental Impact Assessment Review, 30, pp. $363-370,2010$.

[22] Say, N., and Yucel, M., SEA and national development plans in Turkey: towards legal framework and operational procedures, Environmental Impact Assessment Review, 26, pp. 301-316, 2006.

[23] Unalan, D. and Cowell, R., Adoption of EU SEA Directive in Turkey, Environmental Impact Assessment Review, 29, pp. 243-251, 2009. 